\title{
Patients' Preferences of Healthcare Facilities for Quality Healthcare Services in Akwa Ibom State: A Game Theory Approach
}

\author{
Vincenth Udok Udeme, Ukamaka Cynthia Orumie \\ University of Port Harcourt, Port Harcourt, Nigeria \\ Email: amakaorumie@yahoo.com
}

How to cite this paper: Udeme, V.U. and Orumie, U.C. (2021) Patients' Preferences of Healthcare Facilities for Quality Healthcare Services in Akwa Ibom State: A Game Theory Approach. American Journal of Operations Research, 11, 181-198.

https://doi.org/10.4236/ajor.2021.113011

Received: January 19, 2021

Accepted: May 28, 2021

Published: May 31, 2021

Copyright $\odot 2021$ by author(s) and Scientific Research Publishing Inc. This work is licensed under the Creative Commons Attribution International License (CC BY 4.0).

http://creativecommons.org/licenses/by/4.0/

\begin{abstract}
The purpose of this work is to apply Game theory approach to determine patients' preferences of healthcare facilities for quality healthcare in Akwa Ibom State. Cross-sectional descriptive study and purposive sampling technique were adopted in order to collect the relevant data. Factors influencing patients' preferences of health care facilities between public and private hospitals in Akwa Ibom State were assessed using a set of questionnaires which were distributed to 9976 patients in University of Uyo Teaching Hospital, Uyo, Akwa Ibom State. A two-person zero sum game theory approach was applied. Perception of quality healthcare services received by respondent's preferred facilities between public and private hospitals was examined. Also the reasons for patients' persistence of their preferred facilities were evaluated using questionnaire. The optimal strategy and the value of the game were determined using the factors influencing patients' preferences of healthcare facilities, and analysed with two-person-zero-sum game. Facility that gives their clients the best satisfaction was identified. The data collected through questionnaire were analysed using the rules of dominance in a two-person-zero-sum game and TORA statistical software was employed. The result shows that the value of the game, $v=330$ which implies that the game is favourable to public hospital. The result also showed that patients preferred public hospitals due to costs of services with probability one (1), while private hospitals attributed their preferences to attitude of healthcare providers with probability one (1).
\end{abstract}

\section{Keywords}

Health Care Facilities, Cross-Sectional Descriptive Study, Purposive Sampling Technique, Questionnaires, Rules of Dominance 


\section{Introduction}

The healthcare structure in Nigeria is made up of private and public healthcare facilities. In the public sector, healthcare facilities are under the three tiers of government: Federal (tertiary hospital and some hospital in federal institutions like universities), State (state specialist and general hospitals) and Local Government Areas (primary health care centres and health posts). In the private sector, they are broadly categorized into those that provide primary care, those that provide secondary care and those that provide primary and specialist care. There are also several non-governmental organizations and donor-owned and operated facilities. Unlike in many developed nations, healthcare in Nigeria is not universally free.

As reported by the Nigerian Demographic and Health Survey, about $97 \%$ of women and $98 \%$ of men have no health insurance coverage. Healthcare service consumers are therefore bound to make the choice of where to receive healthcare services based on some factors.

The focus of Government is towards improving the lifestyle of its citizens by providing a healthy and safe environment. Citizens' health is a priority and the Health vision has been extended to strengthen the health services provided to the public.

Akwa Ibom State Government has invested a lot in providing such health services to its people through Ministry of Health $(\mathrm{MOH})$; their established health centres and specialty hospitals in every Local Government Area of the State.

Although the effort of Ministry of Health is to raise the efficiency level of its hospitals and to give a high level of healthcare services to the citizens, patients still get their medical treatment in private hospitals due to reasons best known to them.

The individual preferences of healthcare facilities are based on number of factors such as: their taste, satisfaction with the healthcare services, the reorganised quality of healthcare provided by chosen facility, staff attitude, proximity of the preferred facility, availability of drugs, costs of healthcare services, patient queue length/waiting time and others.

It is a fact that the strategies for measuring quality health care services include; the structure, process and outcomes. Where structure describes the context in which care is delivered, including hospital buildings, staff, financing and equipment, process denotes the transactions between patients and health care providers throughout the delivering of healthcare services, and outcomes denote the effects of healthcare on the health status of patients and populations.

Several studies have been carried out to assess patients' take on the quality of health care received, in which most of them were hospital based.

A study [1] to assess patients' perception of quality of hospital services in Ekiti State, Nigeria, found that $75 \%$ of the respondents were satisfied with the quality of services received. In his study, four hospitals out of the twenty-one state government hospitals in Ekiti State were used in data collection.

Several authors have conducted research on malaria care provider choice by examining the factors that influenced malaria care seeking behaviour in order to 
improve the efficiency of current malaria control strategies using multiple regression analysis. Such are research of [2] [3] [4] [5] [6].

Literature has it that works on preference of health care facilities by the patients are categorized into seven [6] factors affecting their preferences; they include: quality healthcare services provided, access to health facilities (proximity), trained and qualified health providers, attitude of healthcare providers, costs of healthcare services, patients satisfaction in quality of healthcare services obtained, availability of infrastructures and drugs, patients long waiting time and others.

[8] presented a research on patient satisfaction with hospital care on effect of demographic and institutional characteristics using logistic regression models. The study compared the quality of healthcare services using patients' preferability. He analysed the level at which a patient's satisfaction grades were related with both his/her demographic characteristics. From the result, he discovered that among demographic characteristics, age, health status and race repeatedly had a statistically significant on patient satisfaction. Also, among institutional characteristics, hospital size consistently had a reasonable effect on patient satisfaction results. Other authors that worked on similar topics are [9]-[14].

[15] analysed the factors that influenced patient's choice of private hospitals against public hospitals in Oman, using Regression and ANOVA. The study revealed that highest respondents preferred private hospitals due to little or no queueing, easier online booking services, timely treatment, and utmost care. $\mathrm{He}$ further discovered that there was a relationship between the selection of the hospitals and cost of health care services. He summarised that services rendered in the hospitals and the cost of services made an impact in the selection of the health facilities for medical treatment by them.

[16] in their research on determinants of consumer satisfaction of health care, discovered that research on factors affecting patient's preference of health care facility in Nigeria has is yet to be completely investigated. These were also reemphasized in [17] where they carried out a research to assess the factors that can influence choice and satisfaction with health service providers among local government staff in Ibadan. The study adopted chi-square and logistic regression in its analysis. The study discovered that many clients utilized public health facilities and attributed the choice to low cost of health care services. The findings showed that private facilities though costlier, did not appear to be providing better services than public facilities. And increasing access to health care, the cost of services and the waiting time were important factors identified.

Literature shows that Game theory has been an area of attraction in the field of social situations amongst competitive groups. Therefore, game theory gives a formal means of explaining optimal strategies under conditions of uncertainty, where the outcome depends on the choices of more than one individual.

Therefore, the researcher wants to analyse patients' preferences of healthcare facilities between private and public hospital using game theory, and the objectives are: 
To examine patients' perception of quality healthcare services received in their preferred facilities between public and private hospitals using questionnaire, to evaluate the reasons for patients' persistence of their preferred facilities, to assess the factors influencing patients' preferences, to determine the optimal strategy and the value of the game using those factors, and to identify which facility between public and private hospitals give their clients the best satisfaction using the value of the game.

Section 2 covers the scope and delimitation of study whereas brief explanation of minimax theorem and methodology is presented in Section 3 and 4 respectively. Section 5 and 6 present analysis and results respectively. Section 7 is summary and conclusions.

\section{Scope and Delimitation of the Study}

This study focuses on patients' preferences of healthcare facilities for quality care services in Akwa Ibom State, using University of Uyo as a case study Teaching Hospital: The only tertiary healthcare facility in Akwa Ibom State with a large patient turnover. It serves as a referral centre to other public and private hospitals. It is used for collection of data for this research. This research data is limited to the data obtained from University of Uyo Teaching Hospital, through a set of administered questionnaires.

It is located at Abak Road, Uyo, Akwa Ibom State. Its distance is about $1 \mathrm{~km}$ away from Ekomiman/Ikot Oku Ikono Junction. This health facility is surrounded by the following communities: on the North by Ikot Ntuen Nsit, on the South by Idoro Obio, Ediene Ikot Obio Imo, on the East by Use Ikot Obio, on the West by Ikot Oku Ikono, all in Akwa Ibom State.

The study will cover only consenting patients (respondents) who will visit the hospital during the study period between February 2019 to September 2019 and willingly comply to fill the questionnaire. The factors to consider in assessing respondents' preferences of healthcare facilities include: provision of quality healthcare services, trained and qualified staff, attitude of health care providers, availability of infrastructure, availability of drugs, costs of services, waiting time and others.

\section{The Minimax Theorem}

The fundamental theorem of game theory [15] states that the situation encountered in the game of Odd-or-Even holds for all finite two-person zero-sum games. Also, the value of the game can be obtained by maximin and minimax principles such that the maximum value and the minimum value are equal for saddle point to exist as the value of the game. The following assumptions hold for every finite two-person zero-sum game:

1) There is a number $V$, called the value of the game.

2) There is a mixed strategy for player I such that I's average gain is at least V no matter what player II does, and there is a mixed strategy for player II such that II's average loss is at most V no matter what player I does. 
3) If $v=0$, then the game is fair.

4) If $v$ is greater than zero $(0)$, then the game is favourable to the row player and vice versa.

\section{Methodology}

The data used for this research are primary data generated from a set of administered questionnaires through a field survey among the consenting patients who visited the hospital during the study period ( $4^{\text {th }}$ February- $6^{\text {th }}$ September 2019). The study adopted the descriptive cross-sectional study and purposive sampling technique for data collection since the population size is unknown. This was to enable the researcher to obtain information on respondents' demographic data and the questions about this study. The researcher grouped the patients choices (respondents) into public and private hospitals and assessed them through questionnaires. Public hospital represents player A that serves as the row player, while private hospital represents player B which serves as the column player. Thus, 10,000 questionnaires were distributed to respondents and 9976 questionnaires were retrieved which represent $99.76 \%$, while 24 questionnaires were unreturned representing $0.24 \%$.

\subsection{A Two-Person Sum Game with Mixed Strategies}

The study adopts a two persons zero-sum game. The payoff matrix is a profit matrix for player A and a loss matrix for player B; the size of the given payoff matrix will be reduced by dominance principles.

If the reduced game matrix is in the form of a square matrix, then optimal strategy solution as well as the value of the game may be obtained by the matrix method as follows:

Let

$$
A=\left[\begin{array}{ll}
a_{11} & a_{12} \\
a_{21} & a_{22}
\end{array}\right]
$$

where

$A$ represents a matrix,

$a_{11}$ represents row 1 column 1 strategy,

$a_{12}$ represents row 1 column 2 strategy,

$a_{21}$ represents row 2 column 1 strategy,

$a_{22}$ represents row 2 column 2 strategy. $I^{*}$

This means, for an $8{ }^{*} 8$ matrix, we have a matrix illustrated as follows:

Player B

$$
\text { Player A }\left[\begin{array}{llllllll}
a_{11} & a_{12} & a_{13} & a_{14} & a_{15} & a_{16} & a_{17} & a_{18} \\
a_{21} & a_{22} & a_{23} & a_{24} & a_{25} & a_{26} & a_{27} & a_{28} \\
a_{31} & a_{32} & a_{33} & a_{34} & a_{35} & a_{36} & a_{37} & a_{38} \\
a_{41} & a_{42} & a_{43} & a_{44} & a_{54} & a_{46} & a_{47} & a_{48} \\
a_{51} & a_{52} & a_{53} & a_{54} & a_{55} & a_{56} & a_{57} & a_{58} \\
a_{61} & a_{62} & a_{63} & a_{64} & a_{65} & a_{66} & a_{67} & a_{68} \\
a_{71} & a_{72} & a_{73} & a_{74} & a_{75} & a_{76} & a_{77} & a_{78} \\
a_{81} & a_{82} & a_{83} & a_{84} & a_{85} & a_{86} & a_{86} & a_{88}
\end{array}\right]
$$


The $8 * 8$ matrix above will further be reduced to a $2 * 2$ matrix using the dominance principle, if there is no saddle point.

To solve the reduced $2 * 2$ game by determining the value of the game and at least one optimal strategy for each player as thus;

Assume there is no saddle point

If $a_{11} \geq a_{12}$, then $a_{12}<a_{22}$, otherwise $a_{12}$ is a saddle point.

Since $a_{12}<a_{22}$, we must have $a_{22}>a_{21}$, as otherwise $a_{22}$ is a saddle point.

$\vdots$

Continuing thus, we see that $a_{21}<a_{11}$ and $a_{11}>a_{12}$

In other words, if $a_{11} \geq a_{12}$, then $a_{11}>a_{12}<a_{22}>a_{21}<a_{11}$

By symmetry, if $a_{11} \geq a_{12}$, then $a_{11}<a_{12}>a_{22}<a_{21}>a_{11}$

This shows that:

If there is no saddle point, then either $a_{11}>a_{12}, a_{12}<a_{22}, a_{22}>a_{21}$ or

$a_{11}<a_{12}, a_{12}>a_{22}, a_{22}<a_{21}$ and $a_{21}>a_{11}$

If player $\mathrm{A}$ chooses the first row with probability $\mathrm{p}$, this implies that he uses the mixed strategy $(p, 1-p)$, we equate his average return when player $\mathrm{B}$ uses columns 1 and 2:

Player B

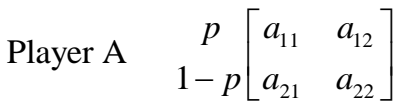

$$
\begin{aligned}
& \text { q } 1-q
\end{aligned}
$$

Then,

$$
a_{11} p+a_{21}(1-p)=a_{21} p+a_{22}(1-p)
$$

Solving for $p$,

Therefore,

$$
p=\frac{a_{22}-a_{21}}{a_{11}-a_{12}-a_{21}+a_{22}}
$$

Since there is no saddle point, $\left(a_{11}-a_{12}\right)$ and $\left(a_{22}-a_{21}\right)$ are either both positive and either both negative: hence, $0<p<1$. Player A's average return using this strategy is

$$
v=a_{11} p+a_{21}(1-p)=\frac{a_{11} a_{22}-a_{12} a_{21}}{a_{11}-a_{12}-a_{21}+a_{22}}
$$

If player B chooses the first column with probability $q$, then he uses strategies $(q, 1-q)$, and equating these average losses when player A uses rows 1 and 2:

$$
a_{11} q+a_{21}(1-q)=a_{21} q+a_{22}(1-q)
$$

Hence,

$$
q=\frac{a_{22}-a_{21}}{a_{11}-a_{12}-a_{21}+a_{22}}
$$

Again, since there is no saddle point, $0<q<1$. Player B's average loss using this strategy is: 


$$
v=a_{11} q+a_{21}(1-q)=\frac{a_{11} a_{22}-a_{12} a_{21}}{a_{11}-a_{12}-a_{21}+a_{22}}
$$

Therefore, the following formulae are used to find the optimal strategies for players A, B and the value of the game:

Player A's optimal strategy

$$
\begin{gathered}
p_{1}=\frac{a_{22}-a_{21}}{a_{11}-a_{12}-a_{21}+a_{22}} \\
p_{2}=1-p_{1}
\end{gathered}
$$

where $p_{1}+p_{2}=1$.

For Player B's optimal strategy $=$

$$
\begin{gathered}
q_{1}=\frac{a_{22}-a_{21}}{a_{11}-a_{12}-a_{21}+a_{22}} \\
q_{2}=1-q_{1}
\end{gathered}
$$

where $q_{1}+q_{2}=1$

$$
v=\frac{a_{11} a_{22}-a_{12} a_{21}}{a_{11}-a_{12}-a_{21}+a_{22}}
$$

or

$$
V=P^{\mathrm{T}} A Q
$$

In general,

$$
p+q=1
$$

where

Player A represents public hospital denoting the row of the payoff matrix.

Player B represents private hospital, denoting the column payoff matrix.

a's represents different payoffs.

$$
\begin{aligned}
& P=\left(p_{1}, p_{2}\right) \\
& Q=\left(q_{1}, q_{2}\right)
\end{aligned}
$$

$p_{1}$ and $p_{2}$ represent the probabilities of player $\mathrm{A}$ using his row strategies respectively.

Then $q_{1}$ and $q_{2}$ represent the probabilities of player B using his column strategies respectively.

$V$ represents the value of the game.

\subsection{Notations}

The following notations are used for the considered strategies to be used in analyses.

$a_{1}$-Provision of quality health care by the public hospitals

$a_{2}$-Trained and qualified staff by the public hospitals

$a_{3}$-Attitude of healthcare providers by the public hospitals

$a_{4}$-Availability of infrastructure by the public hospitals 
$a_{5}$ - Availability of drugs by the public hospitals

$a_{6}$ - Costs of services by the public hospitals

$a_{7}$-Waiting time in the public hospitals

$a_{8}$-Others by the public hospitals

$b_{1}$ - provision of quality health care by the private hospitals

$b_{2}$-Trained and qualified staff by the private hospitals

$b_{3}$-Attitude of healthcare providers by the private hospitals

$b_{4}$-Availability of infrastructure by the private hospitals

$b_{5}$-Availability of drugs by the private hospitals

$b_{6}$ - Costs of services by the private hospitals

$b_{7}$-Waiting time by the private hospitals

$b_{8}$-Others by the private hospitals

The pay of matrix using the above notations gives Table 1 .

\section{Presentation of Data and Analyses}

\subsection{Data Presentation on Respondents' Bio-data and Interpretation}

This chapter is separated into two Sections A and Section B. Section A explains the percentage distribution on demographic data of respondents and Section $B$ questions on the study and their respective analysis.

\subsubsection{Percentage Distribution on Demographic Data of Respondents}

Based on Table 2, it is shown that 3413 respondents were males representing $34 \%$, while 6563 were females representing $66 \%$ as represented in Figure 1.

Table 1. The pay off matrix of the patience preferences.

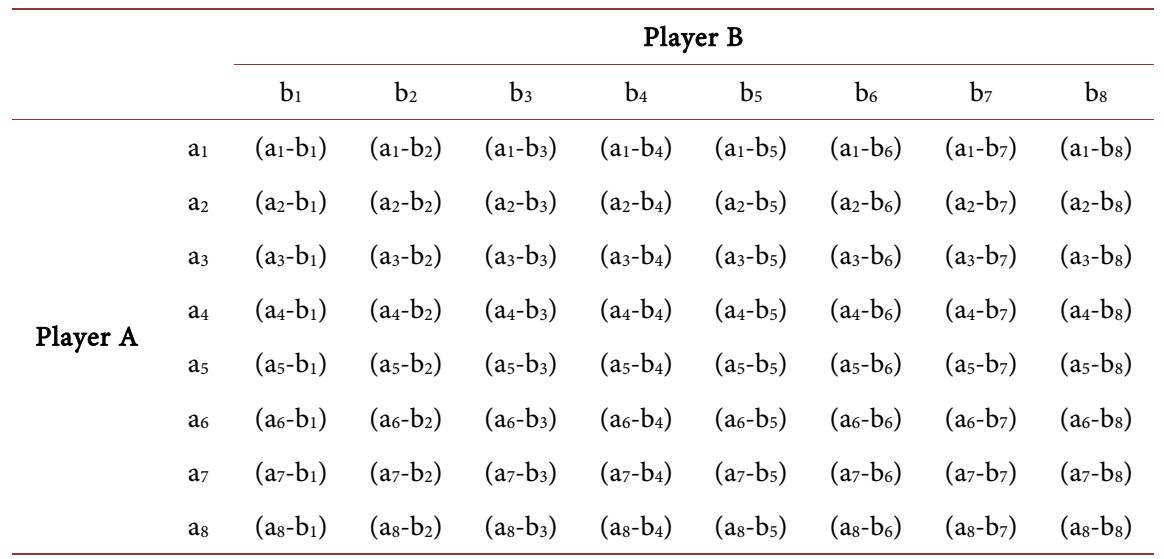

Table 2. Percentage distribution of sex of respondents.

\begin{tabular}{ccc}
\hline Gender & Frequency & Percentage (\%) \\
\hline Male & 3413 & 34 \\
Female & 6563 & 66 \\
Total & 9976 & 100 \\
\hline
\end{tabular}

Source: Questionnaire from field survey. 


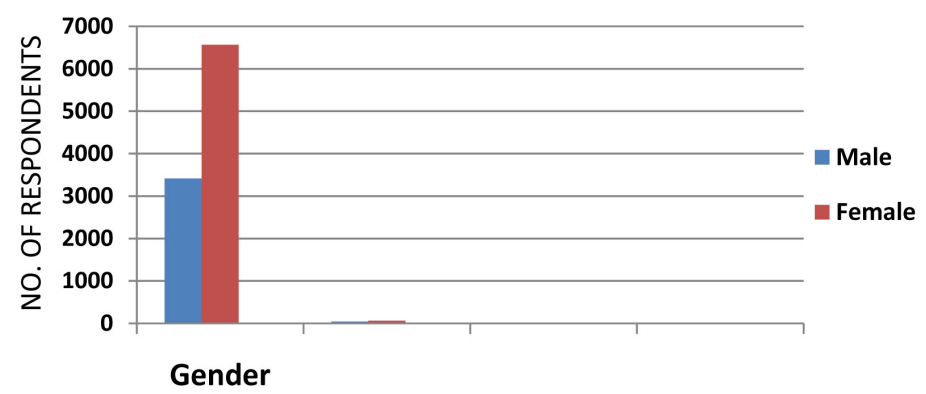

Figure 1. Bar chart showing sex of respondents.

Table 3 shows the percentage distribution on age group of respondents. The table indicates that 75 respondents were between 16 - 20 years representing $1 \%$, 276 respondents were between 21 - 25 years representing 3\%, 962 respondents were between 26 - 30 years representing 9\%, 1395 respondents were between 31 35 years representing 14\%, 1832 respondents were between 36 - 40 years representing 18\%, 2074 respondents were between 41 - 45 years representing $21 \%, 2668$ respondents were between 46 - 50 years representing $27 \%$ and 730 respondents were between 51 years and above representing $7 \%$.

Thus, Figure 2 shows the bar chart representing the explanation of Table 3.

Table 4 indicates that 20\% with 1974 respondents had SSCE and below SSCE, $36 \%$ representing 3635 respondents had diplomas, 38\% representing 3805 respondents had degrees and 6\% with 562 respondents representing others. This is represented using pie chart as shown in Figure 3.

Table 5 indicates that 6185 of respondents represented by $62 \%$ were working class and 3791 respondents represented by $38 \%$ were not working class. The bar char in Figure 4 is representing the distribution of working status as explained above.

Table 6 shows the percentage distribution of respondents by marital status where 1477 respondents represented by $15 \%$ were single, 5701 respondents represented by $57 \%$ were married, 880 respondents represented by $9 \%$ were divorced and 1598 respondents represented by $16 \%$ were widowed and 320 respondents representing $3 \%$.

Therefore, the marital status of respondents is shown in Figure 5 using pie chart.

\subsubsection{Data Presentation on Research Questions and Interpretation}

Question 6: As a consumer of health care services, which of the facility between public and private hospital do you prefer to receive your medical needs?

From Table 7, 5713 respondents represent 57\% in public hospital, while 4263 respondents represent $43 \%$ in private hospital. This is shown in Figure 6, with use of pie chat.

Question 7: Will you like to maintain your preferred hospital throughout your health care needs?

Based on Table 8, 45\% representing 4507 respondents in public hospital 


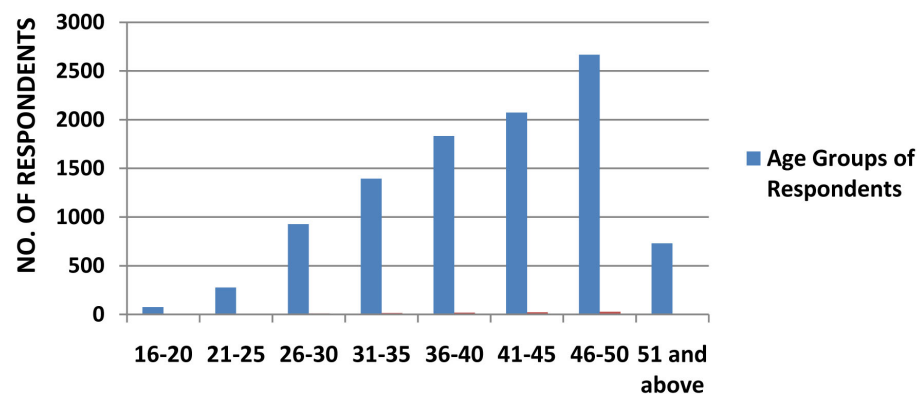

Figure 2. Bar chart illustrates age groups of respondents.

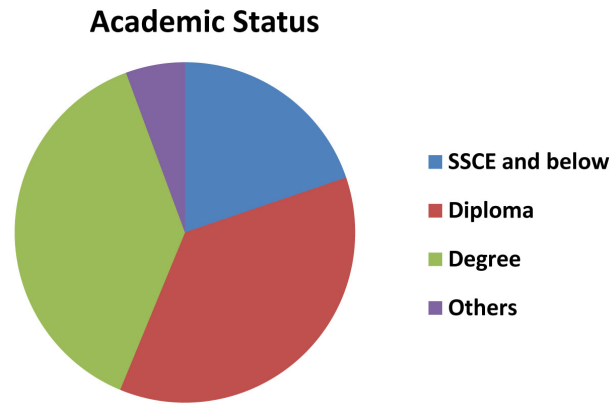

Figure 3. A pie chart showing academic status of respondents.

Table 3. Age distribution of respondents.

\begin{tabular}{ccc}
\hline Age Group & No. of Respondents & Percentage (\%) \\
\hline $16-20$ & 75 & 1 \\
$21-25$ & 276 & 3 \\
$26-30$ & 926 & 9 \\
$31-35$ & 1395 & 14 \\
$36-40$ & 1832 & 18 \\
$41-45$ & 2074 & 21 \\
$46-50$ & 2668 & 27 \\
51 and above & 730 & 7 \\
Total & 9976 & 100 \\
\hline
\end{tabular}

Source: Questionnaire from field survey.

Table 4. Percentage distribution of academic status of respondents.

\begin{tabular}{ccc}
\hline Qualification & No. of Respondents & Percentage (\%) \\
\hline SSCE and below & 1974 & 20 \\
Diploma & 3635 & 36 \\
Degree & 3805 & 38 \\
Others & 562 & 6 \\
Total & 9976 & 100 \\
\hline
\end{tabular}

Source: Questionnaire from field survey. 


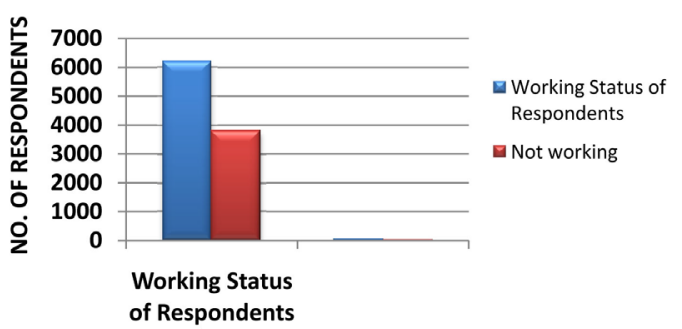

Figure 4. Bar chart showing working status of respondents.

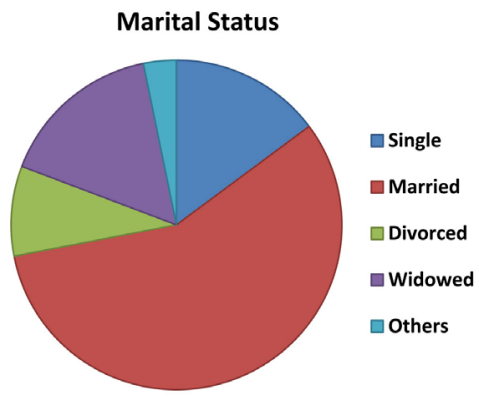

Figure 5. A pie chart showing marital status of respondents.

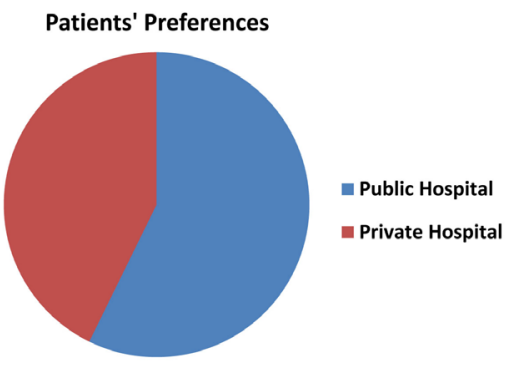

Figure 6. A pie chart showing preferences between public and private hospitals.

Table 5. Percentage distribution of working status of respondents.

\begin{tabular}{ccc}
\hline Status & No. of Respondents & Percentage (\%) \\
\hline Working & 6185 & 62 \\
Not Working & 3791 & 38 \\
Total & 9976 & 100 \\
\hline
\end{tabular}

Source: Questionnaire from field survey.

Table 6. Percentage distribution of marital status of respondents.

\begin{tabular}{ccc}
\hline Status & No. of Respondents & Percentage (\%) \\
\hline Single & 1477 & 15 \\
Married & 5701 & 57 \\
Divorced & 880 & 9 \\
Widowed & 1598 & 16 \\
Others & 320 & 3 \\
Total & 9976 & 100 \\
\hline
\end{tabular}

Source: Questionnaire from field survey. 
agreed to maintain their preferred hospital, while $12 \%$ representing 1206 respondents did not agree to maintain their preferred hospital. Also, 25\% representing 2442 respondents in private hospital agreed to maintain their preferred hospital, while $18 \%$ representing 1821 respondents in private hospital did not agree to maintain their preferred hospital. The bar chart in Figure 7 is representing the opinion on their persistence to choice of facilities.

Question 8: Which of the facility between public and private do you prefer in terms of the following factors? (Table 9)

\subsection{Data Analysis and Interpretation for Question Patience Preferences}

\begin{tabular}{|c|c|c|c|c|c|c|c|c|c|}
\hline & \multicolumn{8}{|c|}{ Player B } \\
\hline & & $b_{1}$ & $\mathrm{~b}_{2}$ & $\mathrm{~b}_{3}$ & $\mathrm{~b}_{4}$ & $\mathrm{~b}_{5}$ & $\mathrm{~b}_{6}$ & $\mathrm{~b}_{7}$ & $\mathrm{~b}_{8}$ \\
\hline \multirow{8}{*}{ 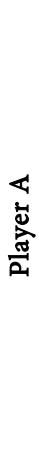 } & $a_{1}$ & $(611,661)$ & $(611,461)$ & $(611,811)$ & $(611,366)$ & $(611,381)$ & $(611,341)$ & $(611,801)$ & $(611,441)$ \\
\hline & $a_{2}$ & $(761,661)$ & $(761,461)$ & $(761,811)$ & $(761,366)$ & $(761,381)$ & $(761,341)$ & $(761,801)$ & $(761,441)$ \\
\hline & $a_{3}$ & $(431,661)$ & $(431,461)$ & $(431,811)$ & $(431,366)$ & $(431,381)$ & $(431,341)$ & $(431,801)$ & $(431,441)$ \\
\hline & $a_{4}$ & $(931,661)$ & $(931,461)$ & $(931,811)$ & $(931,366)$ & $(931,381)$ & $(931,341)$ & $(931,801)$ & $(931,441)$ \\
\hline & $a_{5}$ & $(911,661)$ & $(911,461)$ & $(911,811)$ & $(911,366)$ & $(911,381)$ & $(911,341)$ & $(911,801)$ & $(911,441)$ \\
\hline & $a_{6}$ & $(1141,661)$ & $(1141,461$ & $(1141,811)$ & $(1141,366$ & $(1141,381)$ & $(1141,341$ & $(1141,801$ & $(1141,441)$ \\
\hline & $a_{7}$ & $(361,661)$ & $(361,461)$ & $(361,811)$ & $(361,366)$ & $(361,381)$ & $(361,341)$ & $(361,801)$ & $(361,441)$ \\
\hline & $a_{8}$ & $(566,661)$ & $(566,461)$ & $(566,811)$ & $(566,366)$ & $(566,381)$ & $(566,341)$ & $(566,801)$ & $(566,441)$ \\
\hline
\end{tabular}

Table 7. Patients' preferences of healthcare facilities between public and private hospitals.

\begin{tabular}{ccc}
\hline Public Hospitals & Private Hospitals & Total \\
\hline $5713(57 \%)$ & $4263(43 \%)$ & $9976(100 \%)$ \\
\hline
\end{tabular}

Source: Questionnaire from field survey.

Table 8. Patients' persistence of their preferred facilities public private.

\begin{tabular}{cccc}
\hline Yes & No & Yes & No \\
\hline 4507 & 1206 & 2442 & 1821 \\
$45 \%$ & $12 \%$ & $25 \%$ & $18 \%$ \\
\hline
\end{tabular}

Source: Questionnaire from field survey.

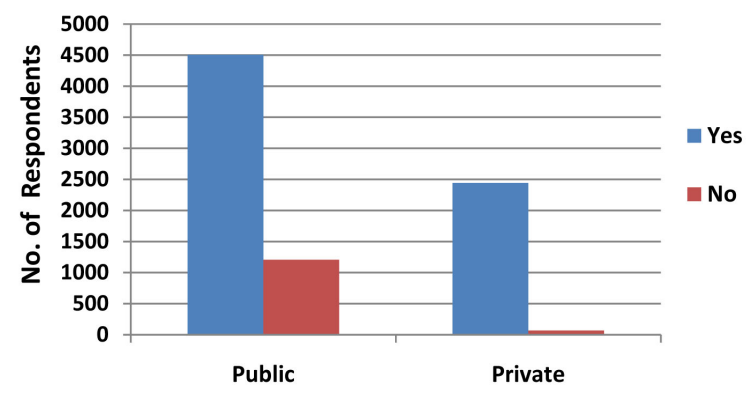

Figure 7. Bar chart showing respondent opinion. 
Table 9. Frequency distribution of responses on the Factors Influencing Patients' decisions.

\begin{tabular}{cccc}
\hline S/N & ITEM & PUBLIC & PRIVATE \\
\hline I & Provision of quality health care & 611 & 661 \\
Ii & Trained and qualified staff & 761 & 461 \\
Iii & Attitude of health care providers & 431 & 811 \\
Iv & Availability of infrastructure & 931 & 366 \\
V & Availability of drugs & 911 & 381 \\
Vi & Costs of services & 1,141 & 341 \\
Vii & Waiting time & 361 & 801 \\
Viii & Others & 566 & 441 \\
& Total & 5713 & 4263 \\
\hline
\end{tabular}

Source: Questionnaire from field survey.

\subsubsection{Data Analysis and Interpretation Using Dominance Rule on the Pay-Off Matrix}

Applying dominance rule to reduce the following matrices to $2 \times 2$ payoff matrix we obtain the following:

\begin{tabular}{|c|c|c|c|c|c|c|c|c|c|}
\hline & & \multicolumn{8}{|c|}{ Player B } \\
\hline & & $b_{1}$ & $\mathrm{~b}_{2}$ & $\mathrm{~b}_{3}$ & $\mathrm{~b}_{4}$ & $\mathrm{~b}_{5}$ & $\mathrm{~b}_{6}$ & $\mathrm{~b}_{7}$ & $\mathrm{~b}_{8}$ \\
\hline \multirow{8}{*}{ 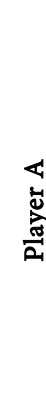 } & $a_{1}$ & -50 & 150 & -200 & 245 & 230 & 270 & -190 & 170 \\
\hline & $\mathrm{a}_{2}$ & 100 & 300 & -50 & 395 & 380 & 420 & -40 & 320 \\
\hline & $a_{3}$ & -230 & -30 & -380 & 65 & 50 & 90 & -370 & -10 \\
\hline & $a_{4}$ & 270 & 470 & 120 & 565 & 550 & 590 & 130 & 490 \\
\hline & $\mathrm{a}_{5}$ & 250 & 450 & 100 & 545 & 530 & 570 & 110 & 470 \\
\hline & $\mathrm{a}_{6}$ & 480 & 680 & 330 & 775 & 760 & 800 & 340 & 700 \\
\hline & $a_{7}$ & -300 & -100 & -450 & -5 & -20 & 20 & -440 & -80 \\
\hline & $\mathrm{a}_{8}$ & -95 & 105 & -245 & 200 & 185 & 225 & -235 & 125 \\
\hline & & & & \multicolumn{6}{|c|}{ Player B } \\
\hline & & & & \multicolumn{2}{|c|}{$b_{3}$} & \multicolumn{2}{|c|}{$\mathrm{b}_{7}$} & \multicolumn{2}{|c|}{ row min } \\
\hline \multirow{2}{*}{\multicolumn{2}{|c|}{$\frac{\mathrm{d}}{\stackrel{\mathrm{a}}{\alpha}}<$}} & \multirow{2}{*}{\multicolumn{2}{|c|}{$\mathrm{a}_{4}$}} & \multicolumn{2}{|c|}{120} & \multicolumn{2}{|c|}{130} & \multicolumn{2}{|c|}{120} \\
\hline & & & & & & & & & \\
\hline \multicolumn{2}{|c|}{ Col max } & & & \multicolumn{2}{|c|}{330} & \multicolumn{2}{|c|}{340} & & \\
\hline
\end{tabular}

Based on the result above, a saddle point exists at 330 since the maximin value $=$ the minimax value. This implies that player A being the public hospital prefers $a_{6}$ strategy, that is representing costs of services with probability 1 . And player $B$ being the private hospital prefers $b_{3}$ strategy, representing attitude of health care providers with probability 1 . Also, the value of the game is 330 . This means that patients prefer public hospitals to private hospitals since the value of the game is greater than zero. In other words, the game is in favour of public hospital.

Question 9: In your own assessment, which of the two facilities stated below will give you the best satisfaction? 
Table 10. Summary on satisfaction levels of patients based on their preferred facilities, with their percentages.

\begin{tabular}{cc}
\hline Public & Private \\
\hline 6959 & 3017 \\
$70 \%$ & $30 \%$ \\
\hline
\end{tabular}

Source: Questionnaire from field survey.

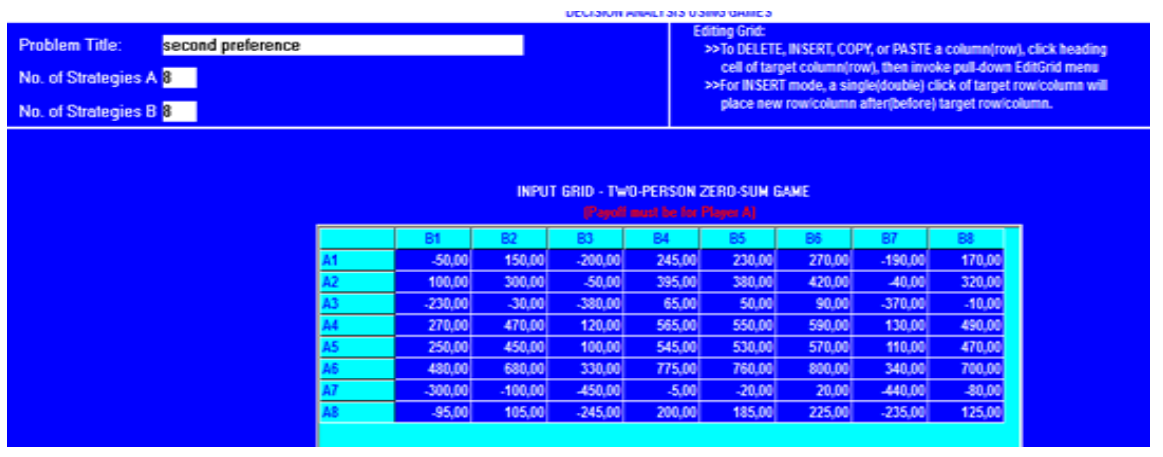

Figure 8. Input data of the pay off matrix.

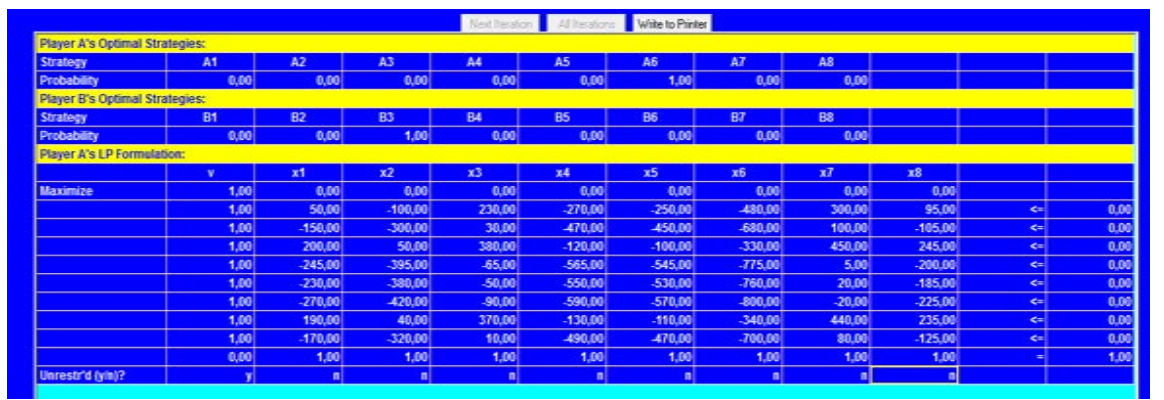

Figure 9. Result output of the pay off matrix.

Based on Table 10 as well as the value of the game, $v=330$ as gotten from the $2 \star 2$ reduced matrix in Section 5.2.1, it implies that patients are more satisfied in patronizing public hospitals than private hospitals.

\subsubsection{Data Analysis with TORA Statistical Software}

Based on Figure $8 \&$ Figure 9, player A's optimal strategies $=(0,0,0,0,0,1,0$, $0)$.

Player B's optimal strategies $=(0,0,1,0,0,0,0,0)$.

The value of the game, $v=330$. This implies that most patients prefer public hospitals due to costs of services, while some patients prefer private hospitals due to attitude of healthcare providers. Also, the value of the game, $v=330$ is much greater than one, which implies that the game is in favor of player A being the public hospital.

\section{Summary, Conclusion and Recommendation}

\subsection{Summary}

This research work was on patients' preferences of health care facilities for qual- 
ity health care services in Akwa-Ibom State. A cross sectional descriptive study was adopted in collaboration with purposive sampling technique to guide the researcher in collecting the relevant data for this study. Primary data were collected through a set of distributed questionnaires from 9976 consenting patients in University of Uyo Teaching Hospital, Uyo, Akwa-Ibom State. Questionnaires were implemented to obtain patients' preference on the quality healthcare services received and the reasons for persistence of their preferred facilities between public and private hospitals in Akwa-Ibom State. The data gathered were analysed using a two-person-zero-sum game with pure strategies by TORA statistical software. Based on this study, dominance principles were adopted to reduce the payoff matrix to $2 \times 2$ in order to achieve our aim. The result showed that the value of the game, $v=330$ was in favour of public hospital since $v$ is greater than zero. However, the study showed that public hospital was preferred due to low costs of services and private hospital preferred attitude of healthcare providers with probability 1 .

\subsection{Conclusion}

Sequel to the results, it is observed that:

Though there are other factors such as provision of quality health care services, trained and skilled staff, availability of infrastructure, availability of drugs, waiting time and others, the most preferred factors by patients are costs of healthcare services for public hospital and attitude of health care providers for private hospital. It was shown that public hospitals attracted more patients due to costs of services whereas private hospitals attracted patients because of attitude of healthcare providers. Patients preferred to patronize public hospitals more than private hospitals since the value of the game is positive.

\subsection{Recommendations}

It is recommended that:

Healthcare providers need to be trained and retrained in order to improve their skills, competence and human relation for quality improvement and clients' satisfaction in both hospitals. Modern equipment, laboratories and facilities should be provided at all health centres/hospitals to reduce the delays in appointment in regards to patient long waiting time. Necessary and sufficient drugs (medicines) should be provided in all the health centres and hospitals. Suggestions and public opinions should be considered so as to maintain the medical standards and to improve quality of services rendered by the public hospitals in order for them to be able to have full dominance of patients' patronage.

Above all, private hospitals should reduce the cost of drugs, whereas public hospitals should improve on their relationships with patients.

\section{Conflicts of Interest}

The authors declare no conflicts of interest regarding the publication of this paper. 


\section{References}

[1] National Population Commission (NPC) [Nigeria] and ICF Macro (2009) Nigeria Demographic and Health Survey 2008. National Population Commission and ICF Macro, Abuja.

[2] Dzator, J. and Asafu, J. (2004) A Study of Malaria Care Providers Choice in Ghana. Health Policy, 69, 389-401. https://doi.org/10.1016/j.healthpol.2004.01.005

[3] Nonvignon, J., Aikens, M.K., Chinbuah, M.A, Abbey, M., Gyapong, M., Garshong, B.N., Fia, S. and Gyapong, J. (2010) Treatment Choices for Fevers in Children Under-Five Years in a Rural Ghanaian. Malaria Journal, 9, Article No 188. https://doi.org/10.1186/1475-2875-9-188

[4] Tembon, A.C. (1996) Health Care Provider Choice: The North West Province of Cameroon. International Journal of Health Planning and Management, 11, 53-67. https://doi.org/10.1002/(SICI)1099-1751(199601)11:1\%3C53::AID-HPM413\%3E3.0. CO;2-A

[5] Rutebemberwa, E., Pariyo, G., Peterson, S., Tomson, G. and Kallander, K. (2009) Utilization of Public or Private Health Care Providers by Febrile Children after User Fee Removal in Uganda. Malaria Journal, 8, Article No. 45. https://doi.org/10.1186/1475-2875-8-45

[6] Young, G.J., Meterko, M. and Desai, K.R. (2000) Patient Satisfaction with Hospital Care: Effects of Demographic and Institutional Characteristics. Medical Care, 38, 325-334. https://doi.org/10.1097/00005650-200003000-00009

[7] Aiken, L.H., Sloane, D., Griffiths, P., Rafferty, A.M., Bruyneel, L., McHugh, M. and Sermeus, W. (2007) Nursing Skill Mix in European Hospitals: Cross Sectional Study of the Association with Mortality, Patients Ratings and Quality of Care. BMJ Safety and Quality, 26, 559-568. https://doi.org/10.1136/bmjqs-2016-005567

[8] Chukmaitov, A., Harless, D.W., Bazzoli, G.J., Carretta, H.J. and Siangphoe, U. (2015) Delivery System Characteristics and Their Association with Quality and Costs of Care: Implications for Accountable Care Organizations. Health Care Management Review, 40, 92-103. https://doi.org/10.1097/HMR.0000000000000014

[9] Gulmez, M. (2005) Satisfaction Measurement in Health Service and an Application to the Clinic for Out-Patient in Cumhuriyet University Hospital. Cumhuriyet University Journal of Economics and Administrative Sciences, 6, 147-169.

[10] Daniel, O.J. (2013) Patient Satisfaction with Health Services at the Out-patient Department of a Tertiary Hospital in Nigeria. Nigerian Journal of Clinical Medicine, 5 , 1-6. https://doi.org/10.4314/njcm.v5i1.2

[11] Williams, H.A. and Jones, C.O. (2004) A Critical Review of Behavioral Issues Related to Malaria Control in Sub-Saharan Africa: What Contributions Have Social Scientists Made? Social Science \& Medicine, 59, 501-523. https://doi.org/10.1016/j.socscimed.2003.11.010

[12] Ray, T.K., Pandav, C.S., Anand, K., Kapoor, S.K. and Dwivedi, S.N. (2002) Out-of-Pocket Expenditure on Healthcare in a North India Village. National Medical Journal of India, 15, 257-260.

[13] Sheikha, M.A. and Khan, F.R. (2017) Factors Influencing the Preference of Private Hospitals to Public Hospitals in Oman. Management, Innovation \& Entrepreneurial Research, 3, 67-77. https://doi.org/10.18510/ijmier.2017.323

[14] Nketiah-Amponsah, E. and Hiemenz, U. (2009) Determinants of Consumer Satisfaction of Health Care in Ghana: Does Choice of Health Care Provider Matter? Global Journal of Health Science, 2, 50-61. https://doi.org/10.5539/ghs.v1n2p50 
[15] Uchendu, O.C., Ilesanmi, O.S. and Olumide, A.E. (2013) Factors Influencing the Choice of Health Care Providing Facility among Workers in a Local Government Secretariat in South Western Nigeria. Annals of Ibadan Postgraduate Medicine, 11, 87-95.

[16] Young, G.J. (2018) Patient Satisfaction with Hospital Care: Effects of Demographic and Institutional Characteristics. Medical Care, 38, 325-340. https://doi.org/10.1097/00005650-200003000-00009

[17] Forgó, F. (2004) John von Neumann's Contribution to Modern Game Theory. Acta Oeconomica, 54, 73-84. https://doi.org/10.1556/aoecon.54.2004.1.5 


\section{Appendix}

\section{SECTION A}

Please tick as appropriate and indicate your options where needed.

1) Gender: Male $\square$ Female

2) Age: 16 - 20 yrs $\square 21-25$ yrs $\square 26-30$ yrs $\square 31-35$ yrs $\square$

36 - 40 yrs $\square 41$ - 45 yrs $\square 46$ - 50 yrs $\square 51$ and Above

3) Academic qualification: SSCE and Below $\square$ Diploma $\square$

Degree $\square$ Others

4) Employment status: Working $\square$ Not working

5) Marital status: Married $\square$ Single $\square$ Divorced

Widowed

Others

\section{SECTION B}

6) As a consumer of healthcare services, which of the facility between public and private hospital do you prefer to receive your medical needs.

Public $\square$ Private

7) Will you like to maintain your preferred hospital throughout your healthcare needs? Yes

If YES, please give your reason(s)

Which of the facility between public and private do you prefer in terms of the following factors:

\begin{tabular}{|c|c|c|c|}
\hline $\mathrm{S} / \mathrm{N}$ & ITEM & PUBLIC & PRIVATE \\
\hline I & Provision of quality healthcare services & & \\
\hline Ii & Trained and qualified staff & & \\
\hline Iii & Attitude of health care providers & & \\
\hline Iv & Availability of infrastructure & & \\
\hline $\mathrm{V}$ & Availability of drugs & & \\
\hline $\mathrm{Vi}$ & Costs of services & & \\
\hline Vii & Waiting time & & \\
\hline Viii & Others & & \\
\hline
\end{tabular}

8) In your own assessment, which of the two facilities stated below will give you the best of satisfaction?

Public Private

Please give your reason(s) 